\title{
Information exchange among physicians caring for the same patient in the community
}

\author{
Carl van Walraven MD MSc, Monica Taljaard PhD, Chaim M. Bell MD PhD, \\ Edward Etchells MD MSc, Kelly B. Zarnke MD, Ian G. Stiell MD MSc, Alan J. Forster MD MSc
}

$\infty \quad$ See related commentary by Reid and Wagner, page 987

\section{ABSTRACT}

Background: The exchange of information is an integral component of continuity of health care and may limit or prevent costly duplication of tests and treatments. This study determined the probability that patient information from previous visits with other physicians was available for a current physician visit.

Methods: We conducted a multicentre prospective cohort study including patients discharged from the medical or surgical services of 11 community and academic hospitals in Ontario. Patients included in the study saw at least 2 different physicians during the 6 months after discharge. The primary outcome was whether information from a previous visit with another physician was available at the current visit. We determined the availability of previous information using surveys of or interviews with the physicians seen during current visits.

Results: A total of 3250 patients, with a total of 39469 previous-current visit combinations, met the inclusion criteria. Overall, information about the previous visit was available $22.0 \%$ of the time. Information was more likely to be available if the current doctor was a family physician (odds ratio [OR] 1.75, 95\% confidence interval [CI] 1.54-1.98) or a physician who had treated the patient before the hospital admission (OR 1.33, 95\% Cl 1.21-1.46). Conversely, information was less likely to be available if the previous doctor was a family physician (OR 0.38, 95\% $\mathrm{Cl} 0.32-0.44)$ or a physician who had treated the patient before the admission (OR $0.72,95 \% \mathrm{Cl} 0.60-0.86$ ). The strongest predictor of information exchange was the current physician having previously received information about the patient from the previous physician (OR 7.72, 95\% Cl 6.92-8.63).

Interpretation: Health care information is often not shared among multiple physicians treating the same patient. This situation would be improved if information from family physicians and patients' regular physicians was more systematically available to other physicians.

Une version française de ce résumé est disponible à l'adresse www.cmaj.ca/cgi/content/full/179/10/1013/DC1

CMAJ 2008;179(10):1013-8

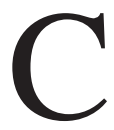
ontinuity of care occurs when patients experience linked care over time and when discrete elements of care are connected. ${ }^{1}$ Overall, most studies have shown a benefit of physician continuity, exemplified by lower utilization of emergency and hospital services, ${ }^{2-5}$ greater use of preventive interventions, ${ }^{6-8}$ improvements in disease-specific symptoms or quality-of-care measures, ${ }^{9}$ and greater patient satisfaction. ${ }^{10,11}$

Continuity of care has been conceptualized as having 3 primary components: ${ }^{1}$ physician continuity, management continuity and information continuity. The root component of information continuity is the availability of data from previous visits by the patient with other physicians. In 3 previous studies, physicians were frequently missing necessary information from visits that patients had made to other physicians. ${ }^{12-14}$ However, none of those studies prospectively followed a well-defined cohort of patients.

To achieve a better understanding of how information exchange might be improved in the community setting, we sought to identify the patient- and physician-related factors that influence the availability of information from previous visits with other physicians.

\section{Methods}

\section{Study design}

We conducted a multicentre prospective cohort study including patients discharged to the community from medical or surgical services of 11 Ontario hospitals in 5 cities after an elective or emergent admission. The 11 hospitals consisted of 6 university-affiliated institutions and 5 community hospitals. We did not include patients who had been discharged to nursing homes. Patients were eligible for enrolment if their cognitive skills were unimpaired, if they had a telephone and if they provided written informed consent.

From the Ottawa Health Research Institute (van Walraven, Taljaard, Stiell Forster); the Departments of Medicine (van Walraven, Taljaard, Forster) and Emergency Medicine (Stiell), University of Ottawa, Ottawa, Ont.; the Institute for Clinical Evaluative Sciences (van Walraven); the Department of Health Policy Management and Evaluation (Bell), University of Toronto; the Department of Medicine (Bell) and the Keenan Research Centre, Li Ka Shing Knowledge Institute (Bell), St. Michael's Hospital; Department of Medicine, Sunnybrook Health Sciences Centre (Etchells), Toronto, Ont.; and the Department of Medicine, Foothills Medical Centre (Zarnke), Calgary, Alta. 
The study was approved by the Ottawa Hospital Research Ethics Board, with subsequent approval by each participating site.

For the purposes of this study, we called the initial physician visit after the patient's discharge from hospital the "index visit." In the analysis, visits for which we determined information availability were called "current visits," and the physician for any such visit was the "current physician." Visits that occurred before the current visit were called "previous visits," and the physician for any such visit was a "previous physician." All nonspecialist physicians were classified as family physicians. Physicians that a patient identified as having provided regular, continuing care before the hospital admission were classified as the patient's "regular physicians."

\section{Data collection and study outcome}

Before each eligible patient's discharge from hospital, a member of the study team interviewed the patient to determine baseline functional status and to identify the patient's regular physicians. We examined the patient's chart and discharge summary, if available, to collect demographic information, a list of chronic medical conditions, information about the hospital stay and medications at discharge. We also determined the Charlson comorbidity index, ${ }^{15}$ which quantifies the severity of chronic illnesses, with values of 5 or more representing the greatest severity. After discharge, a member of the study team contacted each patient by telephone at 1, 3 and 6 months to identify the date and the physician for all visits that occurred after the discharge.

The primary outcome of the study was whether information about the patient from previous physician encounters was available to the current physician. We used 3



Figure 1: Flow diagram showing recruitment and follow-up of patients to determine availability of information about postdischarge physician visits to subsequent physicians. methods to gather the data. First, for any visit to a physician in the 6 months after discharge, we asked the patient to give the physician a paper survey. In this survey, the physician was asked to "List all visits this patient had with other doctors for which you have information (e.g., consult notes, phone calls)." We did not ask for any details about the previous information. The physician returned the completed survey in a postage-paid envelope. Study personnel supplied blank surveys to patients after they were recruited and after each follow-up phone call.

Second, if we did not receive a completed physician survey within 2 weeks after a reported visit, we faxed a copy of a different survey to the physician. This survey listed the dates of all visits that the patient had had with other doctors since the time of discharge, and the physician was asked to indicate whether information about each prior visit had been available for the current visit.

Third, if 4 weeks had passed since the survey was sent by fax and the physician had not returned the survey, we administered the survey by telephone, asking the physician or office personnel to review the patient's chart to determine whether information from other physicians was present. For the analyses in this study, we did not include visits to an emergency department and readmissions to hospital.

\section{Statistical analysis}

We calculated the overall probability of information availability as the number of times that information from previous visits was available divided by the total number of previous-current visit combinations. An illustration of the analytical data set and how it was created appears in Appendix 1 (available online at www.cmaj.ca/cgi/content/full/179/10 /1013/DC2). We calculated the unadjusted association of information availability with categorical patient and physician factors using the average proportion of previous-current visit combinations for which information was available for patients with or without each factor. For continuous variables, we calculated the Pearson correlation coefficient with the proportion of visits for which information was available.

The visits included in our analysis were not independent. Therefore, we used a hierarchical mixed-effects multivariable logistic regression model to determine the independent association between patient, physician and visit factors and information availability. ${ }^{16}$ Details of our modelling strategy are given in Appendix 2 (available online at www.cmaj.ca/cgi /content/full/179/10/1013/DC2).

\section{Results}

Between October 2002 and July 2006, we enrolled 5035 patients from 11 hospitals (Figure 1). Excluding patients who died, moved into a nursing home or were readmitted to hospital, our follow-up rate was $94.9 \%$ (4778 patients) at 30 days, $92.4 \%$ (4652 patients) at 90 days and $87.7 \%$ (4416 patients) at 180 days. We excluded 1785 patients $(35.5 \%)$ because they saw only 1 physician during follow-up $(n=1411)$ or did not have complete data for at least one subsequent visit to the same or another physician $(n=374)$. Of the 3250 patients in- 
cluded in this analysis, $3055(94.0 \%)$ patients were followed for the entire 6 months. The remaining 195 patients had incomplete follow-up (Figure 1).

The mean age of the patients was 62.6 years (standard deviation [SD] 15.7), and 3060 patients (94.2\%) were independent in terms of activities of daily living ${ }^{17}$ (Table 1). The mean number of chronic medical conditions per patient was 2.5 (SD 1.9); however, these conditions were of limited severity, and the Charlson comorbidity index ${ }^{15}$ was 0 for more than $75 \%$ of participants. Slightly more than half of the index admissions were emergent, slightly less than half were under a medical service, about $60 \%$ involved in-hospital consultation with another service, and nearly $70 \%$ occurred at an academic hospital (Table 1).

Table 1: Characteristics of 3250 patients included in a study of information exchange among physicians

\begin{tabular}{|c|c|}
\hline Characteristic & $\begin{array}{l}\text { No. }(\%)^{*} \text { of } \\
\text { patients }\end{array}$ \\
\hline \multicolumn{2}{|l|}{ Demographic } \\
\hline Age, yr, mean (SD) & $62.6(15.7)$ \\
\hline Female & $1733(53.3)$ \\
\hline Lives alone & $751(23.1)$ \\
\hline Has a regular physician & $3152(97.0)$ \\
\hline $\begin{array}{l}\text { Requires no assistance with activities of daily } \\
\text { living }\end{array}$ & $3060(94.2)$ \\
\hline \multicolumn{2}{|l|}{ Medical history } \\
\hline $\begin{array}{l}\text { No. of emergency visits in } 6 \text { mo before index } \\
\text { admission, mean (SD) }\end{array}$ & $0.6 \quad(1.2)$ \\
\hline $\begin{array}{l}\text { No. of admissions in } 6 \text { mo before index } \\
\text { admission, mean (SD) }\end{array}$ & $0.5 \quad(0.9)$ \\
\hline No. of concurrent diagnoses, mean (SD) & $2.5 \quad(1.9)$ \\
\hline \multicolumn{2}{|l|}{ Concurrent conditions } \\
\hline Hypertension & $1380(42.5)$ \\
\hline Dyslipidemia & $695(21.4)$ \\
\hline Diabetes mellitus & $584(18.0)$ \\
\hline Coronary artery disease & $508(15.6)$ \\
\hline Cancer & $417(12.8)$ \\
\hline \multicolumn{2}{|l|}{ Charlson comorbidity indext } \\
\hline 0 & $2476(76.2)$ \\
\hline 1 or 2 & $584(18.0)$ \\
\hline 3 or 4 & $127 \quad(3.9)$ \\
\hline$\geq 5$ & $63(1.9)$ \\
\hline \multicolumn{2}{|l|}{ Index hospital admission } \\
\hline Length of stay, $d$, mean (SD) & $6.9 \quad(9.3)$ \\
\hline No. of complications, mean (SD) & $0.2 \quad(0.5)$ \\
\hline Emergency admission & $1755(54.0)$ \\
\hline Medical service & $1392(42.8)$ \\
\hline In-hospital consultation & $1993(61.3)$ \\
\hline No. of discharge medications, mean (SD) & $5.0 \quad(3.6)$ \\
\hline Admission to academic hospital & $2243(69.0)$ \\
\hline
\end{tabular}

Note: SD = standard deviation.

*Unless indicated otherwise.

†The Charlson comorbidity index ${ }^{15}$ quantifies the severity of chronic illness.
During the study, the patients had a total of 15401 visits to the same or another physician, subsequent to the index visit. For $12469(81.0 \%)$ of these visits, we were able to determine the availability of information from previous patient visits with other doctors. Data for $10088(80.9 \%)$ of these visits came from paper surveys, and the rest (2381 visits, 19.1\%) from phone surveys. The median number of subsequent visits to the same or another physician with complete data was 3 per patient (interquartile range 2-5). Each of these visits was with 1 of 3724 physicians, of whom 1991 (53.5\%) were family physicians.

We included a total of 34969 previous-current visit combinations in the analysis. Information from the previous visit was available for $7711(22.0 \%)$ of the current visits represented by these combinations. Most of the patient demographic and medical factors had little influence on availability of information at the visit (Table 2). However, information was more likely to be available for patients with a regular physician than for those without a regular physician $(21 \%$ v. $14 \%)$. The only characteristic of the index admission that influenced information availability was hospital type, with the probability of information availability being higher for patients who had been admitted to academic hospitals (22\% v. 16\%).

In contrast, physician type strongly influenced information availability (Table 2 and Table 3 ) but had opposite effects for previous and current visits. Information availability was much lower when the previous physician was a family doctor rather than a specialist (unadjusted comparison $8 \%$ v. 30\%; adjusted odds ratio [OR] $0.38,95 \%$ confidence interval [CI] 0.32-0.44). Similarly, information availability was lower when the previous physician was the patient's regular physician (unadjusted comparison $8 \%$ v. 27\%; adjusted OR 0.72 , 95\% CI 0.60-0.86). Information availability was higher when the current physician was a family doctor (unadjusted comparison $32 \%$ v. $13 \%$; adjusted OR $1.75,95 \%$ CI 1.54-1.98) or the patient's regular physician (unadjusted comparison $34 \%$ v. 15\%; adjusted OR 1.33, 95\% CI 1.21-1.46). Information availability was also much higher for the current visit if a report had been received from the previous physician for an earlier visit (unadjusted comparison $53 \%$ v. 17\%; adjusted OR 7.72, 95\% CI 6.92-8.63) or if the patient had a regular physician (unadjusted comparison $21 \%$ v. 14\%; adjusted OR $1.41,95 \%$ CI $1.04-1.91)$.

\section{Interpretation}

Information exchange between physicians who care for the same patient is essential to maintain continuity of care. Our results show that for only $22.0 \%$ of visits did the physician have information from the patient's previous visits with other physicians. Characteristics of the physician and of the visit had a greater effect on information exchange than characteristics of the patient.

Our findings reinforce the results of previous studies showing poor information exchange in health care. In 2 previous studies, researchers measured information exchange by asking physicians if previously collected infor- 
mation (of which they were aware) was unavailable. ${ }^{12,18}$ Information was missing in $14 \%^{12}$ and $32 \%^{18}$ of visits in these 2 studies. In contrast, we explicitly listed all previous visits with other physicians and asked about the availability of information for each previous visit. This difference in

Table 2: Unadjusted association of patient and visit characteristics with availability of information*

\begin{tabular}{|c|c|c|}
\hline \multirow[b]{2}{*}{ Factor } & \multicolumn{2}{|c|}{$\begin{array}{l}\% \text { of visits with information available } \\
\text { from previous visit, }+ \text { mean }\end{array}$} \\
\hline & Factor present & Factor absent \\
\hline \multicolumn{3}{|l|}{ Related to previous visit } \\
\hline With a family physician & 8 & 30 \\
\hline With patients re gular physician $\ddagger$ & 8 & 27 \\
\hline $\begin{array}{l}\text { First visit to a physician after discharge from } \\
\text { index admission }\end{array}$ & 23 & 19 \\
\hline \multicolumn{3}{|l|}{ Related to patient } \\
\hline \multicolumn{3}{|l|}{ Demographic } \\
\hline Female & 20 & 21 \\
\hline Living alone & 22 & 20 \\
\hline Had a regular physician & 21 & 14 \\
\hline $\begin{array}{l}\text { Requires no assistance with activities of daily } \\
\text { living }\end{array}$ & 16 & 21 \\
\hline \multicolumn{3}{|l|}{ Medical history } \\
\hline $\begin{array}{l}\text { At least } 1 \text { hospital admission during } 6 \text { mo } \\
\text { before index admission }\end{array}$ & 22 & 19 \\
\hline $\begin{array}{l}\text { At least } 1 \text { emergency visit in } 6 \text { mo before } \\
\text { index admission }\end{array}$ & 22 & 19 \\
\hline Charlson comorbidity index§ $>0$ & 20 & 20 \\
\hline Hypertension & 19 & 21 \\
\hline Dyslipidemia & 21 & 20 \\
\hline Diabetes mellitus & 20 & 20 \\
\hline Coronary artery disease & 20 & 20 \\
\hline Cancer & 22 & 20 \\
\hline Osteoarthritis & 17 & 21 \\
\hline \multicolumn{3}{|l|}{ Index hospital admission } \\
\hline Emergent admission & 20 & 20 \\
\hline Admission under a medical service & 20 & 20 \\
\hline Academic hospital & 22 & 16 \\
\hline At least 1 in-hospital complication & 20 & 20 \\
\hline At least 1 in-hospital consultation & 19 & 21 \\
\hline \multicolumn{3}{|l|}{ Related to current visit } \\
\hline With a family physician & 32 & 13 \\
\hline With patient's regular physician $\ddagger$ & 34 & 15 \\
\hline Saw patient before previous visit & 24 & 19 \\
\hline $\begin{array}{l}\text { Current physician had previously received } \\
\text { information about the patient }\end{array}$ & 53 & 17 \\
\hline
\end{tabular}

*The following Pearson correlation coefficients were calculated for continuous variables: 0.01 for patient age, -0.03 for length of stay, and -0.03 for number of discharge medications.

†For patient-related factors, we determined the percentage of current visits for which information was available, stratified by the factor for each patient, and then calculated the mean. For visit-related factors, the unit of analysis was the previous physician.

¥Physician who had provided continuing care to the patient before the index hospital admission $\S$ The Charlson comorbidity index ${ }^{15}$ quantifies the severity of chronic illness. methodology explains why information exchange was much lower in our study.

The extensive loss of information shown in the present study, and in previous studies, ${ }^{12,18}$ will decrease continuity of care. Continuity of care has been associated with better patient outcomes, ${ }^{19-21}$ and information continuity is a primary component of overall continuity of care; ${ }^{1}$ we therefore believe that poor exchange of information between physicians caring for the same patient may be detrimental to the quality of patient care. However, it remains to be seen whether increasing the exchange of information will improve health care.

Several factors could explain poor information exchange between physicians. Many physicians write chart notes without creating reports that can be easily transmitted to other physicians. Physicians may be unaware of visits that patients have made to other doctors, or they may feel that getting information about such visits is unnecessary to their care of the patient. Poor information exchange may be largely due to the burden involved. Farber and colleagues ${ }^{22}$ found that communication between physicians consumed up to $5 \%$ of time spent by geriatricians outside of office visits. The time required to improve communication, along with the fact that such activities are not remunerated, ${ }^{23}$ helps explain the poor state of information exchange.

Our data suggest that information exchange could be improved by ensuring that patients have regular physicians and by improving the flow of information from the offices of these regular physicians and family physicians. Other potential solutions include personalized health records. ${ }^{24-27}$ We believe that centralized health information systems could have the greatest benefit for information transmission.

Our results highlight the important but somewhat paradoxical effect of physician type in information exchange. Both family physicians and patients' regular physicians were significantly more likely to receive information from previous visits (Table 3), which illustrates that such physicians serve as information hubs for their patients. However, family physicians and patients' regular physicians were also less likely to transmit information to other physicians. Poor flow of information from family and regular physicians could be due to visits to other 
physicians occurring without their knowledge or to poor communication during the consultation process. ${ }^{28}$

\section{Strengths and limitations}

Our study had several strengths that increase the generalizability of the results. It included a large number of patients from a broad range of services at several teaching and community hospitals, and the rate of follow-up was good. The analysis simultaneously accounted for many important patient-level and system-level factors that might influence information exchange. Finally, the study measured information exchange among all physicians who treated a defined group of patients. This represents an improvement over previous studies, which examined particular physician practices.

Our study also had several limitations. First, we were unable to determine the outcome variable for $19.0 \%$ of visits. However, an $81.0 \%$ response rate compares very well with the results of other survey-based studies. Also, we doubt that the validity of our results would be affected by these missing data, since physician response is unlikely to be associated with information availability. ${ }^{29}$

Second, we did not explicitly ask physicians what type of information they had received for previous visits, nor did we ask them about the quality or necessity of the information, or whether it was helpful. We simply asked physicians if they had "any" information about previous visits with other physicians. We limited the data requested from responding physicians to optimize response rates; however, this simplicity limited our ability to determine the nature and quality of the information available.

Third, our study relied on physician recall. If recall was poor, or if physicians completed the survey long after the original visit, the data they recorded would be less reliable.

Fourth, our study included only patients who had been discharged from hospital. The postdischarge period is frequently characterized by significant shifts in patient care, which could decrease information exchange. Whether our results can be extended to patients who have not received hospital care requires further study.

Fifth, we did not model the administrative or physical links between physicians treating the same patient. For example, we did not specifically model whether different physicians worked in the same practice. Such data could be important in explaining how information flows between physicians.

Sixth, our study was limited to information exchange between physicians. Although visits to other health care professionals are important, we did not capture data about such visits in this study.

\section{Conclusion}

Our study has revealed poor exchange of information between physicians who treat the same patient in the commu-

Table 3: Adjusted association of patient and visit characteristics with availability of information*

\begin{tabular}{|c|c|c|}
\hline Factor & Adjustedt odds ratio $(95 \% \mathrm{Cl})$ & $p$ value \\
\hline \multicolumn{3}{|l|}{ Related to previous visit } \\
\hline With a family physician & $0.38(0.32-0.44)$ & $<0.001$ \\
\hline With patient's regular physician $\ddagger$ & $0.72(0.60-0.86)$ & $<0.001$ \\
\hline First visit to a physician after discharge from index admission & $1.19(1.10-1.29)$ & $<0.001$ \\
\hline \multicolumn{3}{|l|}{ Related to patient } \\
\hline \multicolumn{3}{|l|}{ Demographic } \\
\hline Had a regular physician & $1.41(1.04-1.91)$ & 0.027 \\
\hline Requires no assistance with activities of daily living & $0.93(0.76-1.14)$ & 0.48 \\
\hline \multicolumn{3}{|l|}{ Medical history } \\
\hline At least 1 hospital admission during 6 mo before index admission & $1.04(0.94-1.15)$ & 0.44 \\
\hline Charlson comorbidity index $>0$ & $0.93(0.83-1.05)$ & 0.23 \\
\hline Cancer & $1.15(1.00-1.32)$ & 0.05 \\
\hline \multicolumn{3}{|l|}{ Index hospital admission } \\
\hline Emergent admission & $0.93(0.84-1.02)$ & 0.13 \\
\hline Academic hospital & $1.29(1.14-1.46)$ & $<0.001$ \\
\hline Length of stay & $0.98(0.93-1.04)$ & 0.58 \\
\hline No. of discharge medications & $0.99(0.97-1.00)$ & 0.07 \\
\hline \multicolumn{3}{|l|}{ Related to current visit } \\
\hline With a family physician & $1.75(1.54-1.98)$ & $<0.001$ \\
\hline With patient's regular physician $¥$ & $1.33(1.21-1.46)$ & $<0.001$ \\
\hline Current physician had previously received information about the patient & $7.72(6.92-8.63)$ & $<0.001$ \\
\hline
\end{tabular}

Note: $\mathrm{Cl}=$ confidence interval

*Data based on multivariable logistic regression model.

tEach factor in the model was adjusted for all other factors listed in this table.

$¥$ Physician who had provided continuing care to the patient before the index hospital admission. 
nity. If continuity of patient care is to be increased, interventions and systemic modifications will be needed to improve information exchange.

This article has been peer reviewed.

Competing interests: None declared.

Contributors: All of the authors made substantial contributions to conception and design, or acquisition of data, or analysis and interpretation of data; drafted the article or revised it critically for important intellectual content; and approved the final version of the paper for publication. Dr. van Walraven had full access to all of the data in the study and takes responsibility for the integrity of the data and the accuracy of the data analysis.

Funding: This study was funded by the Canadian Institutes of Health Research, the PSI Foundation, and the Department of Medicine, University of Ottawa.

\section{REFERENCES}

1. Reid R, Haggerty J, McKendry R. Defusing the confusion: concepts and measures of continuity of healthcare. Ottawa: Canadian Health Services Research Foundation; 2002.

2. Burge F, Lawson B, Johnston G. Family physician continuity of care and emergency department use in end-of-life cancer care. Med Care 2003;41:992-1001.

3. Gill JM, Mainous AG 3rd, Nsereko M. The effect of continuity of care on emergency department use. Arch Fam Med 2000;9:333-8.

4. van Walraven C, Mamdani MM., Fang J, et al. Continuity of care and patient outcomes after hospital discharge. J Gen Intern Med 2004;19:624-31.

5. Wasson JH, Sauvigne AE, Mogielnicki RP, et al. Continuity of outpatient medical care in elderly men. A randomized trial. JAMA 1984;252:2413-7.

6. Christakis DA, Mell L, Wright JA, et al. The association between greater continuity of care and timely measles-mumps-rubella vaccination. Am J Public Health 2000;90:962-5.

7. Gill JM, Saldarriaga A, Mainous AG 3rd, et al. Does continuity between prenatal and well-child care improve childhood immunizations? Fam Med 2002;34:274-80.

8. O'Malley AS, Mandelblatt J, Gold K, et al. Continuity of care and the use of breast and cervical cancer screening services in a multiethnic community. Arch Intern Med 1997;157:1462-70.

9. Parchman ML, Pugh JA, Noel PH, et al. Continuity of care, self-management behaviors, and glucose control in patients with type 2 diabetes. Med Care 2002;40:137-44.

10. Hjortdahl P, Borchgrevink CF. Continuity of care: influence of general practitioners' knowledge about their patients on use of resources in consultations. BMJ 1991;303:1181-4
11. Marquis MS, Davies AR, Ware JE Jr. Patient satisfaction and change in medical care provider: a longitudinal study. Med Care 1983;21:821-9.

12. Smith PC, Araya-Guerra R, Bublitz C, et al. Missing clinical information during primary care visits. JAMA 2005;293:565-71.

13. Kripalani S, LeFevre F, Phillips CO, et al. Deficits in communication and information transfer between hospital-based and primary care physicians: implications for patient safety and continuity of care. JAMA 2007;297:831-41.

14. Stiell AP, Forster AJ, Stiell IG, et al. Maintaining continuity of care: a look at the quality of communication between Ontario emergency departments and community physicians. Can J Emerg Med 2005;7:155-61.

15. Charlson ME, Pompei P, Ales KL, et al. A new method of classifying prognostic comorbidity in longitudinal studies: development and validation. J Chronic Dis 1987;40:373-83.

16. Breslow NE, Clayton DG. Approximate inference in generalized linear mixed models. J Am Stat Assoc 1993;88:9-25.

17. Katz S, Akpom CA. A measure of primary sociobiological functions. Int $J$ Health Serv 1976:6:493-508.

18. Stiell A, Stiell IG, Forster AJ, et al. Prevalence of information gaps in the emergency department and the effect on patient outcomes. CMAJ 2003;169:1023-8.

19. Cabana MD, Jee SH. Does continuity of care improve patient outcomes? J Fam Pract 2004;53:974-80

20. Saultz JW, Lochner J, Saultz JW, et al. Interpersonal continuity of care and care outcomes: a critical review. Ann Fam Med 2005;3:159-66.

21. Saultz JW, Albedaiwi W. Interpersonal continuity of care and patient satisfaction: a critical review. Ann Fam Med 2004;2:445-51.

22. Farber J, Siu A, Bloom P. How much time do physicians spend providing care outside of office visits? Ann Intern Med 2007;147:693-8

23. Bodenheimer T. Coordinating care: a major (unreimbursed) task of primary care Ann Intern Med 2007;147:730-1.

24. Elbourne D, Richardson M, Chalmers I, et al. The Newbury Maternity Care Study: a randomized controlled trial to assess a policy of women holding their own obstetric records. Br J Obstet Gynaecol 1987;94:612-9.

25. Latimer EJ, Porterfield P, Roberts JG. A patient care travelling record for palliative care: a feasibility study. J Palliat Care 1991;7:30-6.

26. Shah PM, Selwyn BJ, Shah K, et al. Evaluation of the home-based maternal record: a WHO collaborative study. Bull World Health Organ 1993;71:535-48.

27. van Wersch A, de Boer MF, van der Does E, et al. Continuity of information in cancer care: evaluation of a logbook. Patient Educ Couns 1997;31:223-36.

28. Gandhi TK, Sittig DF, Franklin M, et al. Communication breakdown in the outpatient referral process. J Gen Intern Med 2000;15:626-31.

29. Little RJA, Rubin DB. Statistical analysis with missing data. 2nd ed. New York (NY): Wiley; 2002.

Correspondence to: Dr. Carl van Walraven, Clinical Epidemiology Program, Ottawa Health Research Institute, ASB1-003, Ottawa Hospital, Civic Campus, 1053 Carling Ave., Ottawa ON K1Y 4E9; fax613 761-5355; carlv@ohri.ca

\begin{tabular}{ll|} 
Reprints & \\
Bulk reprints of CMAJ articles are available in minimum quantities of 50 \\
$\begin{array}{l}\text { For information or orders: } \\
\text { Reprint Coordinator } \\
\text { tel } 800663-7336 \times 2110, \text { fax } 613 \text { 565-7704 } \\
\text { janis.murrey@ } @ \text { cma.ca }\end{array}$
\end{tabular}

